\title{
'Diad Analysis' for Linkage Study in Yeast with Poor Spore Viability
}

\author{
By SATOSHI HARASHIMA,* PRAMOD K. SRIVASTAVA, AND \\ YASUJI OSHIMA \\ Department of Fermentation Technology, Faculty of Engineering, Osaka University, \\ Yamada-kami, Suita-shi, Osaka 565, Japan
}

(Received 2 March 1982)

\begin{abstract}
Equations were derived expressing the expected frequencies of the parental ditype (PD), nonparental ditype (NPD) and tetratype (T) as a function of the frequencies of 10 diad types with two spores from double heterozygous diploids. Using these equations, a novel procedure, 'diad analysis' was proposed that permits the estimation of centromere linkage from the frequencies of 10 diad types with two spores. To test the applicability of the diad analysis, the expected numbers of PD, NPD and T asci were calculated using these equations with simulated data for the 10 diad types, taken from tetrad data, and the results were compared, by $\chi^{2}$ statistics, with the observed data from the same tetrads. A good fit was found between the two. A comparison of diad analysis with tetrad analysis and random spore analysis is also discussed.
\end{abstract}

\section{INTRODUCTION}

The four spores in a yeast ascus represent the products of a single meiosis, and analysis of these provides information on recombination and linkage of genes in a heterozygous state. A diploid heterozygous at two loci, $X / x$ and $Y / y$, can produce three types of asci: parental ditype (PD) $X Y X Y x y x y$; non-parental ditype (NPD) $X y X y x Y x Y$; and tetratype (T) $X Y X y x Y x y$. It is possible to determine the positions of the two genes relative to each other from the ratio of PD :NPD :T asci. This method for analysing the linkage relationship is known as tetrad analysis (Desborough \& Lindegren, 1959). However, we sometimes encounter strains with poor spore viability, which do not produce more than two viable spores. In this case, it is still possible to determine the linkage relationship by 'random spore analysis' assuming the randomness of lethality. In contrast to tetrad analysis, however, random spore analysis provides no estimate of the extent, if any, of centromere linkage. To overcome this disadvantage, we have developed a procedure for estimating centromere linkage from the relative frequencies of incomplete tetrad types with two spores. We refer to each such ascus type as a diad (Srivastava et al., 1981), as opposed to a tetrad, and term this procedure 'diad analysis'. As one of a series of mapping studies (Harashima \& Oshima, 1976, 1977), this communication describes theoretical equations to express the frequencies of the diad types from diploids heterozygous for two genes. A comparison of diad analysis with tetrad analysis is also described.

\section{THEORY}

Frequencies of the ten diad types. It is possible to pick up two of four ascospores in six combinations, i.e. (spore A, spore B), (spore A, spore C), (spore A, spore D), (spore B, spore C), (spore B, spore D) and (spore C, spore D). With respect to two genes, these six combinations can form ten diad types, X1 to X10 (Table 1). The origin of each of these ten diad types can in fact be traced back to the original tetrad types, i.e., PD, T or NPD. For instance, XI and $\mathrm{X} 3$ would be of PD origin whereas X2 could originate from either PD or T (see Table 1). The frequencies of X1 to $\mathrm{X} 10$, referred to as $X_{1}$ to $X_{10}$, can be expressed as functions of PD, NPD and T as follows:

$$
\begin{aligned}
& x_{1}=\mathrm{PD} / 6 \\
& x_{2}=2 \mathrm{PD} / 3+\mathrm{T} / 6 \\
& x_{3}=\mathrm{PD} / 6
\end{aligned}
$$


Table 1. Ten possible configurations of diads and their relationship with the original tetrad asci in a doubly heterozygous ( $X Y / x y)$ diploid

$\begin{array}{cccl}\text { Diad type } & \overbrace{\text { A }} & \text { B } & \text { Origin } \\ \text { X1 } & X Y & X Y & \text { PD } \\ \mathrm{X} 2 & X Y & x y & \mathrm{PD}, \mathrm{T} \\ \mathrm{X} 3 & x y & x y & \mathrm{PD} \\ \mathrm{X} 4 & X Y & X y & \mathrm{~T} \\ \mathrm{X} 5 & X Y & x Y & \mathrm{~T} \\ \mathrm{X} 6 & X y & x Y & \mathrm{~T}, \mathrm{NPD} \\ \mathrm{X} 7 & x y & x Y & \mathrm{~T} \\ \mathrm{X} 8 & x y & X y & \mathrm{~T} \\ \mathrm{X} 9 & X y & X y & \mathrm{NPD} \\ \mathrm{X} 10 & x Y & x Y & \mathrm{NPD}\end{array}$

$$
\begin{aligned}
& x_{4}=\mathrm{T} / 6 \\
& x_{5}=\mathrm{T} / 6 \\
& x_{6}=2 \mathrm{NPD} / 3+\mathrm{T} / 6 \\
& x_{7}=\mathrm{T} / 6 \\
& x_{8}=\mathrm{T} / 6 \\
& x_{9}=\mathrm{NPD} / 6 \\
& x_{10}=\mathrm{NPD} / 6
\end{aligned}
$$

If we substitute the PD, NPD and T for $1: 1: 4$ (the ratio in the case of complete non-linkage in tetrad analysis) in the above equations, we get the ratio $1: 8: 1: 4: 4: 8: 4: 4: 1: 1$ between the values of $X_{1}$ to $X_{10}$. This ratio represents complete non-linkage in diad analysis, and any deviation from this will suggest centromere or gene-togene linkage. To determine a precise linkage relationship, however, we need accurate values of PD, NPD and T. In order to express PD, NPD and T values using $X_{1}$ to $X_{10}$, which are obtained from diad data, equations (1) to (10) were rewritten as equations (11) to (20):

$$
\begin{aligned}
& \mathrm{PD}=6 X_{1} \\
& \mathrm{PD}=3 X_{2} / 2-\mathrm{T} / 4 \\
& \mathrm{PD}=6 X_{3} \\
& \mathrm{~T}=6 X_{4} \\
& \mathrm{~T} \quad=6 X_{5} \\
& \mathrm{NPD}=3 X_{6} / 2-\mathrm{T} / 4 \\
& \mathrm{~T}=6 X_{7} \\
& \mathrm{~T}=6 X_{8} \\
& \mathrm{NPD}=6 X_{9} \\
& \mathrm{NPD}=6 X_{10}
\end{aligned}
$$

Thus, given observed values for $\mathrm{X} 1$ to $X 10$, we can calculate PD, NPD and T values directly, using equations (11) to (20) [except for equations (12) and (16)]. For instance, one of the PD values would be $6 \times X_{1}$, using equation (11). In the same manner, $6 \times X_{3}$ can give another PD value (equation 13). However, these two PD values may be slightly different. The same situation can occur for NPD and T values. To minimize the deviation and to obtain unified values of PD, NPD and T, all of the observed data for X1 to X10 should be included in calculation of PD, NPD and T. However, if the average of $X_{4}, X_{5}, X_{7}$ and $X_{8}$ is used as the T value, the contribution of $X_{2}$ and $X_{6}$ towards $\mathrm{T}$ is ignored. In order to assess and include the same in the $\mathrm{T}$ value, we derived the $\mathrm{T}$ value as a function of 
$X_{2}$ and $X_{6}$ by combining equations (2) and (6) with the equation PD $+\mathrm{NPD}+\mathrm{T}=N$, where $N$ is the total number of asci:

$$
\mathrm{T}=2 N-3 X_{2}-3 X_{6}
$$

Now, the final T value can be represented as the average of T values from equations (14), (15), (17), (18) and (21):

$$
\mathrm{T}=\left(6 X_{4}+6 X_{5}+6 X_{7}+6 X_{8}+2 N-3 X_{2}-3 X_{6}\right) / 5
$$

Similarly, the final value of PD can be represented as the average of its values from equations (11), (12) and (13), after substituting the value of $T$ from equation (21) in equation (12):

$$
\mathrm{PD}=\left[6 X_{1}+6 X_{3}+3 X_{2} / 2-\left(6 X_{4}+6 X_{5}+6 X_{7}+6 X_{8}+2 N-3 X_{2}-3 X_{6}\right) / 20\right] / 3
$$

In the same way, the final NPD value is the average of its values from equations (16), (19) and (20), after substituting the value of $\mathrm{T}$ from equation (21) into equation (16):

$$
\mathrm{NPD}=\left[6 X_{9}+6 X_{10}+3 X_{6} / 2-\left(6 X_{4}+6 X_{5}+6 X_{7}+6 X_{8}+2 N-3 X_{2}-3 X_{6}\right) / 20\right] / 3
$$

Thus, derived values of PD, NPD and T can be obtained from the observed number of ten types of diads using equations (22), (23) and (24). Now, expressing PD, NPD, and T in terms of their frequencies, i.e., $a_{1}, a_{2}$ and $a_{3}$ :

$$
\begin{aligned}
& a_{3}=\mathrm{T} / N \\
& a_{1}=\mathrm{PD} / N \\
& a_{2}=\mathrm{NPD} / N
\end{aligned}
$$

\section{RESULTS}

\section{Experimental test of the procedure}

Because four spores in tetrad data are randomly arrayed, tetrad data can be considered as diad data, assuming that two spores in each ascus could not germinate. To test the applicability of diad analysis, tetrad data were scored as diads with only three of six possible combinations, i.e. (spore A, spore B), (spore A, spore C), and (spore A, spore D), since a complementary pair of combinations gives the same values of PD, NPD and $T$. We have tested these three combinations with three gene pairs, i.e., leu2-trp1, lys2-trp1, and his4-leu2, which represent three typical examples of tight centromere linkage, non-linkage and direct linkage between two

\begin{tabular}{|c|c|c|c|c|c|c|c|c|c|}
\hline \multirow[b]{2}{*}{ Diad type } & \multicolumn{3}{|c|}{ leu2-trpl } & \multicolumn{3}{|c|}{ lys2-trpl } & \multicolumn{3}{|c|}{ his4-leu2 } \\
\hline & AB & $\mathrm{AC}$ & $A D$ & $\mathrm{AB}$ & $\mathrm{AC}$ & $A D$ & AB & $\mathrm{AC}$ & $\mathrm{AD}$ \\
\hline X1 & 2 & 6 & 2 & 2 & 2 & 1 & 14 & 15 & 15 \\
\hline $\mathrm{X} 2$ & 16 & 9 & 11 & 15 & 17 & 18 & 56 & 51 & 45 \\
\hline X3 & 0 & 1 & 4 & 3 & 1 & 3 & 2 & 8 & 14 \\
\hline X4 & 1 & 3 & 2 & 7 & 8 & 4 & 4 & 2 & 1 \\
\hline$\times 5$ & 4 & 0 & 3 & 5 & 6 & 10 & 2 & 5 & 5 \\
\hline X6 & 11 & 18 & 12 & 11 & 10 & 9 & 6 & 2 & 2 \\
\hline $\mathrm{X} 7$ & 0 & 2 & 2 & 8 & 10 & 5 & 2 & 3 & 4 \\
\hline X8 & 1 & 1 & 0 & 6 & 5 & 8 & 0 & 1 & 1 \\
\hline $\mathrm{X} 9$ & 7 & 2 & 5 & 2 & 1 & 1 & 0 & 0 & 0 \\
\hline$\times 10$ & 1 & 1 & 2 & 1 & 0 & 1 & 1 & 0 & 0 \\
\hline otal & 43 & 43 & 43 & 60 & 60 & 60 & 87 & 87 & 87 \\
\hline
\end{tabular}
genes, respectively. Actual values of $X_{1}$ to $X_{10}$ for the three gene pairs scored with respect to each combination, i.e., AB, AC and AD, are shown in Table 2. These were used to calculate

\section{Table 2. Actual numbers of ten types of diads for gene pairs leu2-trp1, lys2-trp1 and his4-leu2}

Media composition and general methods for ascus dissection, and characterization of genetic traits were as described by Takano \& Oshima (1967). The diads were created by simulating random abortion in complete tetrad data; $\mathrm{AB}, \mathrm{AC}$ and $\mathrm{AD}$ represent the spore pairs selected for making the diad. 
Table 3. $\chi^{2}$ test between the number of PD, NPD and T asci obtained from tetrad data and simulated diad data for gene pairs, leu2-trp1, lys2-trp1 and his4-leu2

Numbers in parentheses indicate the number of asci, obtained by multiplying the frequencies by the total number of asci in the case of diad analysis and by direct counting in the case of tetrad analysis. Each term of PD, NPD and T asci in which the expected occurrence of asci is less than five was not included for the calculation of $\chi^{2}$ statistics. Calc., calculated; d.f., degrees of freedom.

\begin{tabular}{|c|c|c|c|c|c|c|c|c|}
\hline \multirow[b]{2}{*}{$\begin{array}{l}\text { Analytical } \\
\text { method }\end{array}$} & \multirow[b]{2}{*}{$\begin{array}{c}\text { Spore } \\
\text { combination }\end{array}$} & \multirow[b]{2}{*}{$\begin{array}{c}\text { Tetrad } \\
\text { distribution* }\end{array}$} & \multicolumn{6}{|c|}{ Gene pair } \\
\hline & & & \multicolumn{2}{|r|}{ leu2-trp1 } & \multicolumn{2}{|r|}{ lys2-trpl } & \multicolumn{2}{|r|}{ his4-leu2 } \\
\hline \multirow[t]{3}{*}{$\begin{array}{c}\text { Tetrad } \\
\text { (observed) }\end{array}$} & & $\begin{array}{l}a_{1} \\
a_{2} \\
a_{3}\end{array}$ & & $\begin{array}{l}0.37(16) \\
0.40(17) \\
0.23(10)\end{array}$ & & $\begin{array}{l}0 \cdot 22(13) \\
0 \cdot 10(6) \\
0 \cdot 68(41)\end{array}$ & & $\begin{array}{l}0.83(72) \\
0 \cdot 01(1) \\
0 \cdot 16(14)\end{array}$ \\
\hline & & Total & & $1 \cdot 00(43)$ & & $1.00(60)$ & & $1 \cdot 00(87)$ \\
\hline & & & Calc. & Normalized & Calc. & Normalized & Calc. & Normalized \\
\hline \multirow[t]{4}{*}{$\begin{array}{c}\text { Diad } \\
\text { (deduced) }\end{array}$} & A-B & $\begin{array}{l}a_{1} \\
a_{2} \\
a_{3}\end{array}$ & $\begin{array}{l}0 \cdot 26 \\
0 \cdot 48 \\
0 \cdot 19\end{array}$ & $\begin{array}{l}0 \cdot 28(12 \cdot 07) \\
0.52(22 \cdot 19) \\
0 \cdot 20(8 \cdot 74)\end{array}$ & $\begin{array}{l}0.23 \\
0.13 \\
0.72\end{array}$ & $\begin{array}{l}0 \cdot 21(12 \cdot 64) \\
0 \cdot 12(7 \cdot 02) \\
0 \cdot 67(40 \cdot 34)\end{array}$ & $\begin{array}{l}0.69 \\
0.06 \\
0.08\end{array}$ & $\begin{array}{l}0.83(72 \cdot 35) \\
0 \cdot 07(5.96) \\
0 \cdot 10(8.69)\end{array}$ \\
\hline & & Total & 0.93 & $1 \cdot 00(43 \cdot 00)$ & 1.08 & $1 \cdot 00(60 \cdot 00)$ & 0.83 & $1 \cdot 00(87 \cdot 00)$ \\
\hline & & $\begin{array}{c}\text { d.f. } \\
\chi^{2} \\
\text { Probability (\%) }\end{array}$ & & $\begin{array}{c}2 \\
2 \cdot 67 \\
30>P>20\end{array}$ & & $\begin{array}{c}2 \\
0 \cdot 17 \\
95>P>90\end{array}$ & & $\begin{array}{c}2 \\
7 \cdot 37 \\
5>P>2\end{array}$ \\
\hline & & & Calc. & Normalized & Calc. & Normalized & Calc. & Normalized \\
\hline \multirow[t]{4}{*}{$\begin{array}{c}\text { Diad } \\
\text { (deduced) }\end{array}$} & $\mathrm{A}-\mathrm{C}$ & $\begin{array}{l}a_{1} \\
a_{2} \\
a_{3}\end{array}$ & $\begin{array}{l}0.41 \\
0 \cdot 33 \\
0 \cdot 19\end{array}$ & $\begin{array}{l}0.44(19 \cdot 00) \\
0 \cdot 36(15 \cdot 27) \\
0 \cdot 20(8 \cdot 73)\end{array}$ & $\begin{array}{l}0.18 \\
0.06 \\
0.71\end{array}$ & $\begin{array}{l}0.19(11.53) \\
0.06(3.65) \\
0.75(44 \cdot 82)\end{array}$ & $\begin{array}{l}0 \cdot 81 \\
0 \cdot 00 \\
0 \cdot 19\end{array}$ & $\begin{array}{l}0 \cdot 81(70 \cdot 70) \\
0 \cdot 00(0 \cdot 00) \\
0 \cdot 19(16 \cdot 30)\end{array}$ \\
\hline & & Total & 0.93 & $1 \cdot 00(43 \cdot 00)$ & 0.95 & $1 \cdot 00(60 \cdot 00)$ & 1.00 & $1.00(87 \cdot 00)$ \\
\hline & & $\begin{array}{c}\text { d.f. } \\
\chi^{2} \\
\text { Probability }(\%)\end{array}$ & & $\begin{array}{c}2 \\
0.85 \\
70>P>50\end{array}$ & & $\begin{array}{c}1 \\
0 \cdot 52 \\
50>P>30\end{array}$ & & $\begin{array}{c}1 \\
0 \cdot 34 \\
70>P>50\end{array}$ \\
\hline & & & Calc. & Normalized & Calc. & Normalized & Calc. & Normalized \\
\hline \multirow[t]{3}{*}{$\begin{array}{c}\text { Diad } \\
\text { (deduced) }\end{array}$} & A-D & $\begin{array}{l}a_{1} \\
a_{2} \\
a_{3}\end{array}$ & $\begin{array}{l}0 \cdot 38 \\
0 \cdot 44 \\
0 \cdot 27\end{array}$ & $\begin{array}{l}0 \cdot 35(15 \cdot 00) \\
0 \cdot 40(17 \cdot 28) \\
0 \cdot 25(10 \cdot 72)\end{array}$ & $\begin{array}{l}0.23 \\
0.09 \\
0.59\end{array}$ & $\begin{array}{l}0 \cdot 26(15 \cdot 33) \\
0 \cdot 10(6 \cdot 06) \\
0 \cdot 64(38 \cdot 61)\end{array}$ & $\begin{array}{l}0.91 \\
0.00 \\
0.23\end{array}$ & $\begin{array}{l}0.80(69 \cdot 54) \\
0 \cdot 00(0 \cdot 00) \\
0 \cdot 20(17.46)\end{array}$ \\
\hline & & Total & $1 \cdot 09$ & $1 \cdot 00(43 \cdot 00)$ & 0.91 & $1.00(60 \cdot 00)$ & $1 \cdot 14$ & $1 \cdot 00(87.00)$ \\
\hline & & $\begin{array}{c}\text { d.f. } \\
\chi^{2} \\
\text { Probability }(\%)\end{array}$ & & $\begin{array}{c}2 \\
0 \cdot 13 \\
95>P>90\end{array}$ & & $\begin{array}{c}2 \\
0 \cdot 69 \\
80>P>70\end{array}$ & & $\begin{array}{c}1 \\
0 \cdot 78 \\
50>P>30\end{array}$ \\
\hline
\end{tabular}

${ }^{*} a_{1}, a_{2}$, and $a_{3}$ represent the ratio of the number of PD, NPD and T asci, respectively.

derived values of PD, NPD and T using equations (22), (23) and (24), and also $a_{1}, a_{2}$ and $a_{3}$ using equations (25), (26) and (27). These calculated $a_{1}, a_{2}$ and $a_{3}$ values should total 1 in the ideal case; however, as shown in Table 3, they exceed or fall short of this by a little in almost all cases. We attribute this to the fact that these values of $a_{1}, a_{2}$ and $a_{3}$ represent the averages of more than one PD, NPD and T values from the equations (11) to (20), and thus deviate slightly from the ideal values. As each value is independent of the other two with respect to this deviation in either the positive or the negative direction, the deviation is expressed in the total. Furthermore, since these values have been compared with those obtained from tetrad data, which indeed total 1, we have normalized our derived values so as to total 1 . These normalized values were used to calculate the corresponding number of asci (appearing in parentheses in Table 3), which were then compared with the tetrad values by the $\chi^{2}$ test. A good fit $(P>20 \%)$ was obtained between 
calculated values from diad data and directly observed ones in all cases except the A-B combination with the his4-leu2 gene pair. This discrepancy might be due to the fluctuation of recombination frequencies in the present tetrad sample, as is evident from an unusually high $a_{1}$ value. Thus, the experimental test described above vindicates the validity of our theoretical procedure of diad analysis for linkage studies.

\section{DISCUSSION}

Comparison of the PD, NPD and T values obtained from complete tetrad data and from diads produced as a result of simulated random abortion showed a good fit between the two. This makes diad analysis a convenient and useful tool in cases where tetrad analysis is not possible. Diad analysis has a better resolving power than random spore analysis, which can only indicate the position of the two genes relative to each other, but not relative to the centromere. We attribute this difference in resolution to the fact that in random spore analysis, each spore is an individual unit, whereas in diad analysis it can be traced back to its original tetrad without ambiguity in every case (except in diads X2 and X6, which could originate from PD or T, and NPD or T tetrads, respectively). We have been able to eliminate this ambiguity by suitable mathematical treatment (equation 21).

Our novel procedure for linkage analysis as described above avoids the laborious backcrossing of segregants more than once in order to obtain diploids with high-viability tetrads. It will thus be helpful in cases in which only two spores of a tetrad can be collected due to poor viability. It should be noted, however, that this analysis is applicable only if all the markers, including the unmapped gene in question, show 1:1 segregation en masse for wild type and mutant alleles, because a $1: 1$ ratio assures that the marker in question is segregating independently of spore-lethality.

We wish to thank Dr R. B. Wickner for his critical reading of the manuscript and valuable suggestions.

\section{REFERENCES}

Desbrough, S. \& Lindegren, G. (1959). Chromosome mapping of linkage data from Saccharomyces by tetrad analysis. Genetica 30, 346-383.

HaRashima, S. \& Oshima, Y. (1976). Mapping of homothallic genes, $H M \alpha$ and $H M a$, in Saccharomyces yeasts. Genetics $84,437-451$.

Harashima, S. \& Oshima, Y. (1977). Frequencies of twelve ascus-types and arrangement of three genes from tetrad data. Genetics 86, 535-552.
Srivastava, P. K., Harashima, S. \& Oshima, Y. (1981). Formation of two-spored asci by interrupted sporulation in Saccharomyces cerevisiae. Journal of General Microbiology 123, 39-48.

TaKano, I. \& Oshima, Y. (1967). An allele specific and a complementary determinant controlling homothallism in Saccharomyces oviformis. Genetics 57, 875-885. 